\title{
In vitro Vascular Effects Produced by Crude Aqueous Extract of Green Marine Algae, Cladophora patentiramea (Mont.) Kützing, in Aorta from Normotensive Rats
}

\author{
Yee-Ling Lim Shiueh-Lian Mok \\ Department of Pharmacology, Faculty of Medicine, University of Malaya, Kuala Lumpur, Malaysia
}

\section{Key Words}

Aorta - Endothelium-dependent vasorelaxation • Nitric

oxide $\cdot$ Seaweed

\begin{abstract}
Objectives: To investigate the antihypertensive activity of aqueous extracts obtained from Malaysian coastal seaweeds and to determine the pharmacological mechanisms of the extracts on rat aorta in vitro. Materials and Methods: The antihypertensive activity of 11 species of seaweeds ( 5 brown, 1 red and 5 green algae) were tested by cumulative addition of the extracts to phenylephrine (PE)-precontracted WistarKyoto (WKY) aortic rings in in vitro isometric contraction studies. Mechanisms for vasorelaxant effect were investigated in the presence of various antagonists. Results: Of the 11 species tested, 2 showed a vasorelaxant effect. Further investigation of the mechanisms of action of the aqueous extract of green alga, Cladophora patentiramea (AECP), showed that the vascular relaxant effect was endothelium- and concentration-dependent. A maximum relaxation of $45.8 \pm$ $4.6 \%$ ( $n=8, p<0.001$ ) was obtained at $0.1 \mathrm{mg} / \mathrm{ml}$ of extract, after which the response was found to reduce in a concentration-dependent manner to $15.7 \pm 4.9 \%(n=8, p<0.001)$ at the highest extract concentration tested. Pretreatment of
\end{abstract}

endothelium-intact aortic rings with $\mathrm{N} \omega$-nitro-L-arginine methyl ester (L-NAME, $30 \mu \mathrm{M}),{ }^{1} \mathrm{H}$-[1,2,4]oxadiazolo[4,3-a]quinoxalin-1-one (ODQ, $10 \mu \mathrm{M})$ and methylene blue (100 $\mu \mathrm{M})$ resulted in a complete blockade of AECP-induced vasorelaxation. However, the relaxant effects of the extract were not blocked by atropine $(1 \mu \mathrm{M})$, indomethacin $(10 \mu \mathrm{M})$ and glibenclamide $(10 \mu \mathrm{M})$, although the maximum relaxant responses were enhanced in the presence of glibenclamide. Conclusion: Our data showed that the in vitro vascular relaxant effect of AECP was mediated through endotheliumdependent nitric oxide-cGMP pathway, and was not associated with the release of vasodilator prostaglandins, activation of muscarinic receptors, or ATP-sensitive potassium channels opening.

Copyright $\odot 2010$ S. Karger AG, Basel

\section{Introduction}

Marine macroalgae, more commonly known as seaweed, are utilized in various industries, especially the hydrocolloid industry [1]. Prior to the 1950s, medicinal and pharmaceutical uses of seaweed only occurred in traditional and folk medical treatments [2]. However, in recent years exploitation of products extracted from seaweed in

\section{KARGER \\ Fax +41613061234 \\ E-Mail karger@karger.ch}

www.karger.com
(C) 2010 S. Karger AG, Basel

$1011-7571 / 10 / 0194-0260 \$ 26.00 / 0$

Accessible online at:

www.karger.com/mpp
Dr. Shiueh-Lian Mok, Associate Professor

Department of Pharmacology, Faculty of Medicine

University of Malaya

50603 Kuala Lumpur (Malaysia)

Tel. +60 37967 4950, Fax +60 37967 4791, E-Mail josephinemok@um.edu.my 
medical and biochemical research has led to the discovery of compounds with biological activities or pharmacological properties [1]. For example, wakame (Undaria pinnatifida), a most widely consumed brown seaweed in Japan, has been shown to produce an hypotensive effect in hypertensive human [3]. Further studies on wakame revealed that peptides derived from wakame are potent angiotension I-converting enzyme (ACE) inhibitors and oral administration of these ACE inhibitory peptides in spontaneously hypertensive rats (SHR) shows antihypertensive effect [4-6].

Ren et al. $[7,8]$ showed that the powdered form of some dried seaweed such as Laminaria ochotensis, Gloiopeltis tenax and Porphyra yezoensis, and algal polysaccharides such as funoran, fucoidan, alginate and porphyran, produced marked antihypertensive and antihyperlipidemic effect in animal studies. However, the pharmacological mechanism(s) of the hypotensive effect of the seaweed or seaweed extracts is not fully understood.

In this study, we screened 11 species of seaweeds, collected from the Malaysian coastal waters, and investigated further the vasorelaxant effect and its pharmacological mechanisms of action of one species, Cladophora patentiramea (a green alga) in rings of Wistar-Kyoto (WKY) rat aorta in vitro.

\section{Materials and Methods}

Plant Material and Preparation of Crude Aqueous Extract

Seaweed samples were collected from Cape Rachado and Pantai Dickson of Port Dickson, Negeri Sembilan, on the western coast of the Malaysian Peninsula. Five species of green algae (C. patentiramea, Cheatomorpha linum, Caulerpa racemosa, Caulerpa lentillifera and Caulerpa spp.), 5 species of brown algae (Padina tetrastromatica, Turbinaria conoides, Sargassum binderi, Sargassum baccularia and Sargassum siliquosum) and 1 species of red alga (Gracilaria salicornia) were collected. The identity of the seaweeds was confirmed by Prof. Phang Siew Moi in the Algae Research Laboratory, University of Malaya, and herbarium vouchers were kept as references. The seaweeds were then cleaned, air-dried and coarsely powdered. Crude aqueous extract of each species of seaweed was obtained by exhaustive extraction of the coarsely powdered algae with distilled water at room temperature. The concoction was filtered after every $24 \mathrm{~h}$ and the combined filtrates were lyophilized. The lyophilized extract was kept at $-20^{\circ} \mathrm{C}$ until further use.

\section{Animals}

Male Wistar-Kyoto (WKY) normotensive rats weighing 250$350 \mathrm{~g}$ were used. The animals were obtained from the central animal house located in the Faculty of Medicine, University of Malaya. All the experimental procedures were performed in accordance with guidelines issued by the animal care and use committee of Faculty of Medicine.

Seaweed Extract Induces Vasorelaxation in Rats
Preparation of Rat Aortic Rings

The rats were killed by stunning and exsanguination. The descending thoracic aorta was carefully excised and immediately placed in a dissecting dish containing oxygenated ice-cold modified Krebs-Henseleit solution with the following composition, in mM: $\mathrm{NaCl} 118.4, \mathrm{KCl} 4.7, \mathrm{CaCl}_{2} 1.25, \mathrm{MgSO}_{4} 1.2 \mathrm{NaHCO}_{3} 24.9$, $\mathrm{KH}_{2} \mathrm{PO}_{4} 1.2$ and glucose 11.1. Connective tissue and fat adhering to aorta were removed with great care. The cleaned aorta was then cut into transverse rings of 2.5-3 mm length. In experiments using endothelium-denuded aortic rings, the endothelial layer was removed mechanically by inserting the tip of a pair of fine forceps into the lumen of the aortic ring and gently rotating the ring around the forceps. All dissection procedures were carried out with extreme care to prevent the vascular endothelium and smooth muscle from being inadvertently damaged.

\section{Isometric Tension Recording}

The thoracic aortic rings prepared were then suspended in 10$\mathrm{ml}$ organ baths containing modified Krebs-Henseleit solution at $37^{\circ} \mathrm{C}$ and aerated with a mixture of $\mathrm{O}_{2}(95 \%)$ and $\mathrm{CO}_{2}(5 \%)$. The rings were mounted by inserting 2 parallel L-shaped stainlesssteel hooks into the lumen. The lower hook was attached to the base of the organ bath and the upper hook was connected to a force-displacement transducer (Grass FT03E, Quincy, Mass., USA) which was in turn connected to a preamplifier and data acquisition system (QUAD Bridge and Powerlab, ADInstruments, Australia). A preload of $1 \mathrm{~g}$ resting tension was applied to the aortic rings and changes in tension were recorded on the Powerlab system.

\section{Chemicals and Drugs}

Acetylcholine chloride, phenylephrine hydrochloride, indomethacin, N $\omega$-nitro-L-arginine methyl ester (L-NAME) and atropine were obtained from Sigma-Aldrich (St. Louis, Mo., USA). Glibenclamide was obtained from Tocris (Bristol, UK). ${ }^{1} \mathrm{H}-[1,2,4]$ oxadiazolo[4,3-a]quinoxalin-1-one (ODQ) was obtained from Calbiochem (Darmstadt, Germany). Methylene blue was obtained from Hopkin and Williams (Essex, UK). Potassium chloride and D-glucose were obtained from $\mathrm{BDH}$ (Dorset, UK). Sodium chloride, sodium hydrogen carbonate, magnesium sulfate, calcium chloride and potassium dihydrogen phosphate were obtained from Merck (New Jersey, N.J., USA). Indomethacin was dissolved in sodium bicarbonate (0.5\%). Glibenclamide was dissolved in dimethyl sulfoxide (DMSO). The final concentration of DMSO was adjusted to less than $0.1 \%(\mathrm{v} / \mathrm{v})$. Lyophilized crude aqueous extract was reconstituted in Krebs solution. All other drugs, including Krebs solution, were freshly prepared in distilled water.

\section{Experimental Protocols}

Prior to the initiation of the experimental procedures, the aortic rings were allowed to equilibrate for $60 \mathrm{~min}$, during which the solution was renewed twice and the resting tension was re-adjusted to $1 \mathrm{~g}$, as required. Thereafter, the aortic rings were challenged twice with $80 \mathrm{mM}$ potassium chloride $(\mathrm{KCl})$ to test their functional integrity. After the second $\mathrm{KCl}$-induced contraction, the baths were repeatedly washed out and allowed to re-equilibrate for $30 \mathrm{~min}$. The integrity of the vascular endothelium was then determined by adding acetylcholine (ACh, $1 \mu \mathrm{M})$ to phenylephrine (PE, $0.3 \mu \mathrm{M})$-precontracted aortic rings. A relaxation of 
Table 1. Percentage yield of the crude aqueous extracts derived from various species of seaweeds

\begin{tabular}{llll}
\hline Species & $\begin{array}{l}\text { Weight of } \\
\text { dried } \\
\text { powdered } \\
\text { seaweeds, g }\end{array}$ & $\begin{array}{l}\text { Weight of } \\
\text { lyophilized } \\
\text { aqueous } \\
\text { extract, g }\end{array}$ & $\begin{array}{l}\text { Yield } \\
\%\end{array}$ \\
& & & \\
\hline Brown algae & 63.25 & 5.23 & 8.3 \\
$\quad$ Padina tetrastromatica & 38.18 & 2.43 & 6.4 \\
$\quad$ Sargassum binderi & 45.23 & 2.79 & 6.2 \\
$\quad$ Sargassum baccularia & 25.07 & 1.12 & 4.5 \\
$\quad$ Sargassum siliquosum & 54.52 & 3.84 & 7.0 \\
$\quad$ Turbinaria conoides & & & \\
Red alga & 19.97 & 0.86 & 4.3 \\
$\quad$ Gracilaria salicornia & & & \\
Green algae & 21.71 & 4.12 & 19.0 \\
$\quad$ Caulerpa racemosa & 15.63 & 2.28 & 14.6 \\
$\quad$ Caulerpa lentillifera & 37.43 & 4.76 & 12.7 \\
$\quad$ Caulerpa spp. & 13.09 & 0.51 & 3.9 \\
$\quad$ Cheatomorpha linum & 71.17 & 6.62 & 9.3 \\
$\quad$ Cladophora patentiramea & & & \\
\hline
\end{tabular}

$\geq 75 \%$ of the PE-induced contraction was considered representative of an acceptable presence of functional endothelial layer. Aortic rings with less than $75 \% \mathrm{ACh}$-induced relaxation were not used for further experimentation. For denuded aortic rings, the successful removal of the endothelium was confirmed when ACh failed to produce relaxation.

Determination of the Vascular Effects of the Crude Aqueous

Extracts Derived from Various Species of Seaweeds

Forty-five minutes after the confirmation of endothelial integrity, aortic rings with functional endothelium were pre-contracted with $0.3 \mu \mathrm{M}$ PE. Increasing concentrations of the seaweed crude aqueous extracts $(1 \mathrm{ng} / \mathrm{ml}-3 \mathrm{mg} / \mathrm{ml})$ were added cumulatively at the plateau of PE-induced precontraction. Control aortic rings were also allowed to run concurrently over time without the addition of extracts at the plateau of PE-induced contraction.

Characterization of the C. patentiramea Aqueous ExtractInduced Vasorelaxation Effect in WKY Rat Aortic Rings

Forty-five minutes after the confirmation of endothelial integrity, aortic rings with or without functional endothelium were pre-contracted with $0.3 \mu \mathrm{M}$ PE. Increasing concentrations of $C$. patentiramea aqueous extract (AECP; $1 \mathrm{ng} / \mathrm{ml}-3 \mathrm{mg} / \mathrm{ml}$ ) were added cumulatively at the plateau of $\mathrm{PE}$-induced precontraction. To investigate the involvement of endothelium-derived relaxant factors in the extract-induced relaxation, aortic rings with functional endothelium were preincubated for $10 \mathrm{~min}$ with nitric oxide synthase inhibitor (L-NAME; $30 \mu \mathrm{M}$ ) and $30 \mathrm{~min}$ with nonselective cyclooxygenase inhibitor, indomethacin $(10 \mu \mathrm{M})$, prior to performing cumulative concentration-response (CCR) curves to AECP extract. To evaluate the possible participation of NOcGMP relaxant pathway, CCR curves to AECP extract were per- formed in aortic rings preincubated for $30 \mathrm{~min}$ with soluble guanylate cyclase (sGC) inhibitors (ODQ; $10 \mu \mathrm{M}$ ) and 30 min with methylene blue $(100 \mu \mathrm{M})$. To characterize the involvement of cholinergic mechanisms, aortic rings were preincubated with muscarinic receptors antagonist atropine $(1 \mu \mathrm{M}) 15$ min prior to addition of PE. Lastly, to examine the possible role of ATP-sensitive potassium channels $\left(\mathrm{K}_{\mathrm{ATP}}\right)$ on the AECP effects, CCR curves to the extract were performed in aortic rings in the presence of the $\mathrm{K}_{\mathrm{ATP}}$ channel blocker glibenclamide $(10 \mu \mathrm{M})$ after $10 \mathrm{~min}$ of preincubation.

\section{Statistical Analysis}

The results are expressed as the mean \pm SEM of $n$ number of observations. Statistical analysis was performed using GraphPad Prism 4.0 (GraphPad Software, USA) and data were compared by 2-way analysis of variances (ANOVA) followed by Bonferroni's post-test. A p value less than 0.05 was considered statistically significant.

\section{Results}

\section{Yield of Crude Aqueous Extracts Derived from}

Various Species of Seaweeds

The yield of the crude aqueous extracts being tested for vasorelaxant effect in the WKY rat aortic rings is given in table 1. Three green algae (Caulerpa racemosa, Caulerpa lentillifera and Caulerpa spp.) in that descending order had the highest yield of 19.0, 14.6 and $12.7 \%$.

\section{Effects of Crude Aqueous Extracts Derived from}

Brown Algae on WKY Rat Aortic Rings

Of the 5 species of brown algae tested, only crude aqueous extracts derived from $P$. tetrastromatica caused vascular relaxation in WKY aortic rings. Cumulative concentration-response curve of $P$. tetrastromatica water extract showed a triphasic action of the extract on the rings (fig. 1). The extract induced an initial vasoconstriction in the aortic rings, followed by a significant vascular relaxant effect which was reduced as higher concentrations of extract were added into the organ bath. Crude aqueous extracts derived from Sargassum species and Turbinaria conoides did not elicit any vasorelaxation in WKY rat aortic rings but induced a significant vasoconstrictor effect on the rings.

\section{Effects of Crude Aqueous Extracts Derived from Red}

Algae on WKY Rat Aortic Rings

Crude aqueous extracts obtained from G. salicornia did not cause any vasorelaxation in WKY aortic rings. However, a slight vasoconstriction effect was observed when higher concentrations of extract were added into the organ bath (fig. 2). 
Fig. 1. Effects of crude aqueous extracts derived from various species of brown algae on phenylephrine $(0.3 \mu \mathrm{M})$-precontracted aortic rings isolated from WistarKyoto normotensive rats. The results show the mean \pm SEM of 8-20 observations. ${ }^{* *} \mathrm{p}<0.01$ and ${ }^{* * *} \mathrm{p}<0.001$ when compared to the phenylephrine control.

Fig. 2. Effects of crude aqueous extracts derived from red alga, Gracilaria salicornia, on phenylephrine $(0.3 \mu \mathrm{M})$-precontracted aortic rings isolated from WistarKyoto normotensive rats. The results show the mean \pm SEM of 6-12 observations. ${ }^{* * *} \mathrm{p}<0.001$ when compared to the phenylephrine control.

Seaweed Extract Induces Vasorelaxation in Rats
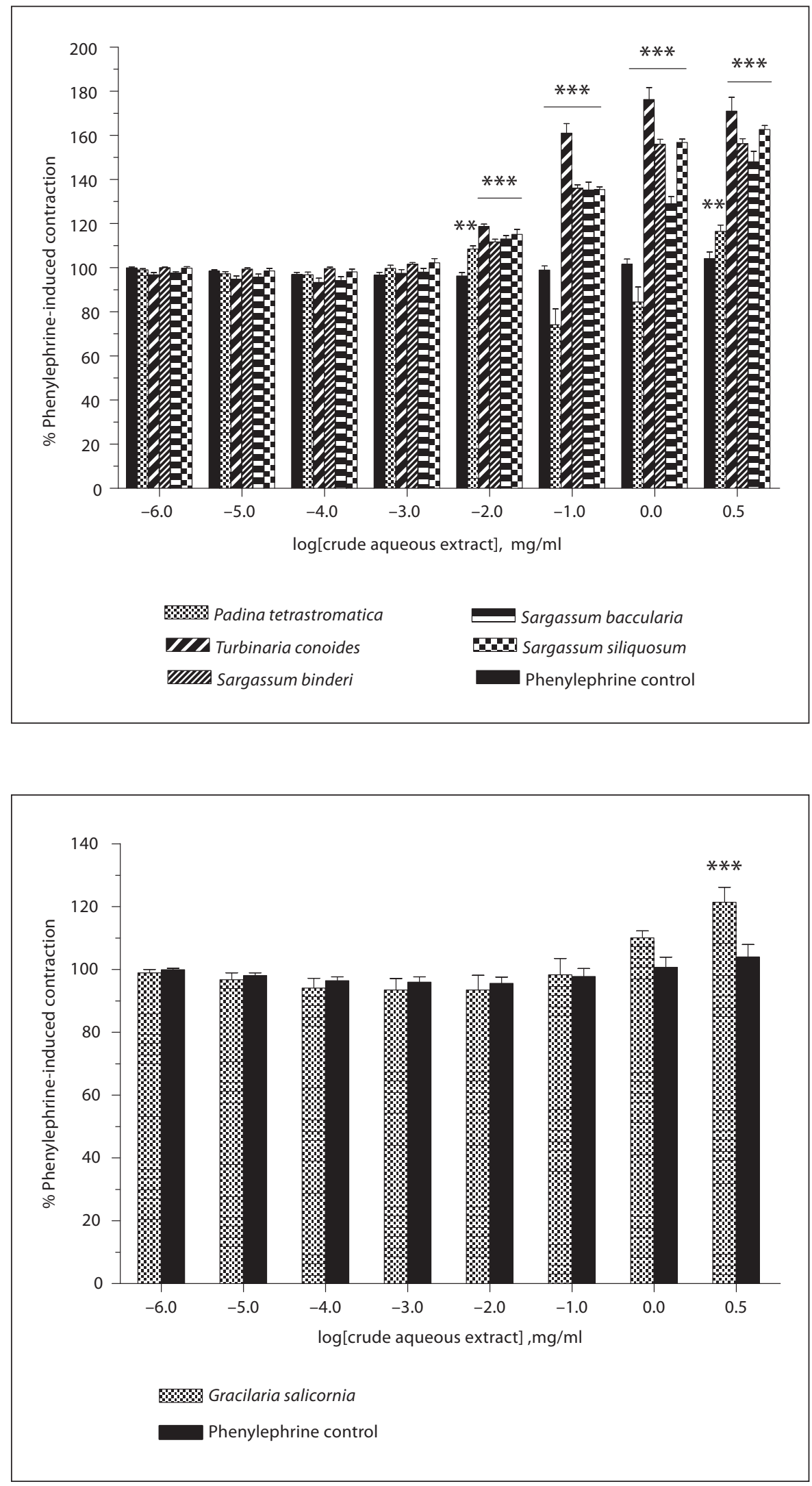
Fig. 3. Effects of crude aqueous extracts derived from various species of green algae on phenylephrine $(0.3 \mu \mathrm{M})$-precontracted aortic rings isolated from Wistar-Kyoto normotensive rats. The results show the mean \pm SEM of $8-16$ observations. ${ }^{*} \mathrm{p}<$ 0.05 and ${ }^{* * *} \mathrm{p}<0.001$ when compared to the phenylephrine control.

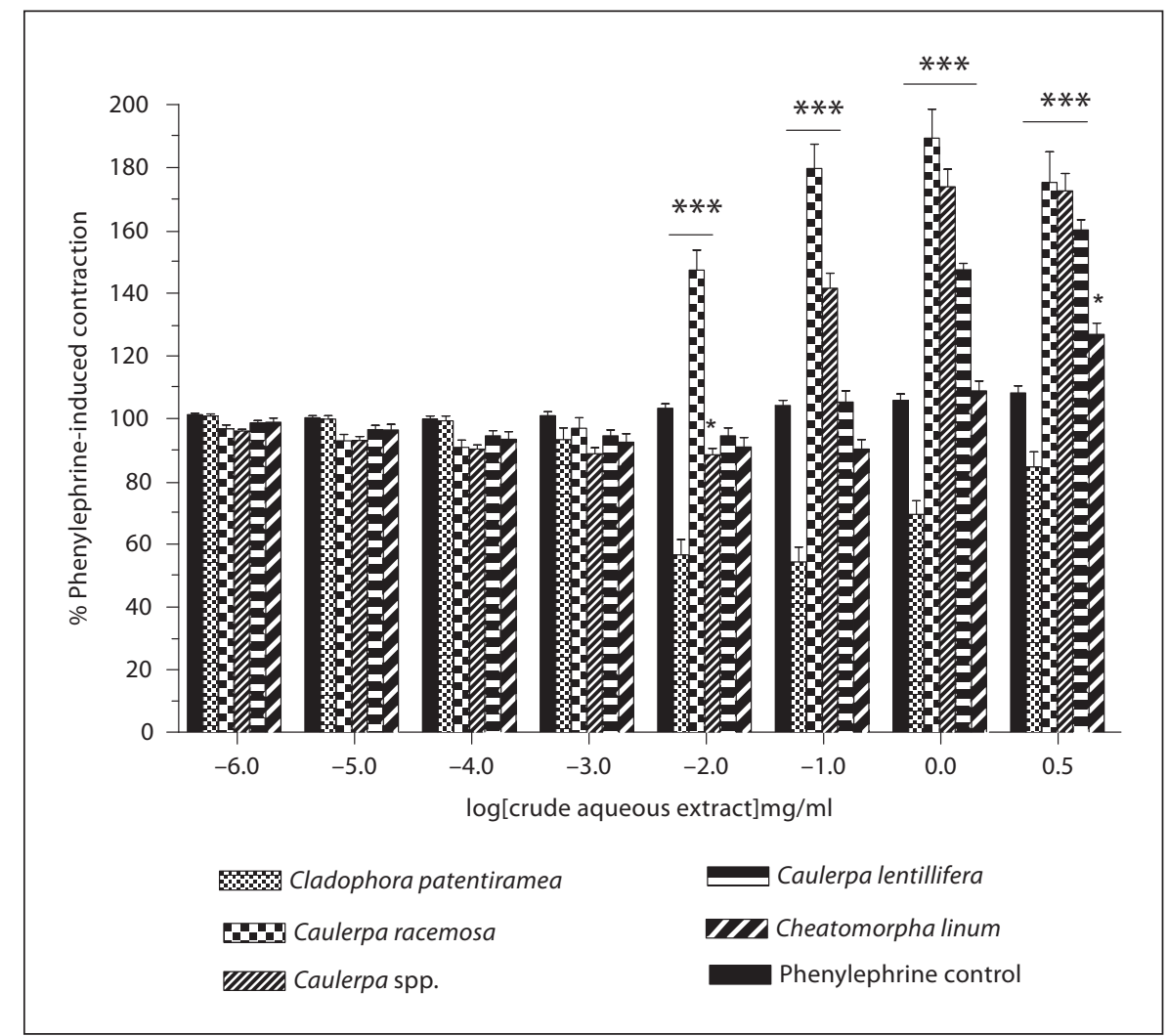

Effects of Crude Aqueous Extracts Derived from Green Algae on WKY Rat Aortic Rings

Crude aqueous extracts of the Caulerpa species (i.e. C. lentillifera, C. racemosa, and Caulerpa spp.) caused significant vasoconstriction of aortic rings at higher extract concentrations. The extracts did not elicit any effects on the aortic rings at lower concentrations. Similarly, crude aqueous extracts derived from Cheatomorpha linum also failed to elicit vasorelaxant action on the rings. The vasoconstriction induced by the extract at higher extract concentrations was smaller in magnitude compared to that elicited by the extracts of the Caulerpa species. Crude AECP, however, was able to elicit significant vasorelaxant effect in WKY rat aortic rings (fig. 3).

\section{Endothelium-Dependent Vasodilation of Crude AECP} on Rat Aortic Rings

Addition of cumulative concentrations of AECP at the plateau of PE-induced contraction caused a significant and concentration-dependent vasorelaxant action on endothelium-intact aortic rings at extract concentrations ranging from $1 \mathrm{ng} / \mathrm{ml}$ to $0.1 \mathrm{mg} / \mathrm{ml}$. A maximum relaxation of $45.8 \pm 4.6 \%(\mathrm{n}=8, \mathrm{p}<0.001)$ was obtained at
$0.1 \mathrm{mg} / \mathrm{ml}$ of extract, after which the response was found to be reduced in a concentration-dependent manner to $15.7 \pm 4.9 \%(\mathrm{n}=8, \mathrm{p}<0.001)$ at the highest extract concentration tested (fig. 4). On the other hand, AECP (1 ng/ $\mathrm{ml}-3 \mathrm{mg} / \mathrm{ml}$ ) was unable to elicit any vascular relaxant effect on endothelium-denuded aortic rings (fig. 5). The vasodilator effects of AECP are clearly endothelium-dependent as its effects on aortic rings without functional endothelium were similar to that produced by the control rings in figure 4.

\section{Involvement of NO-cGMP Pathway on AECP-Induced Relaxation}

The vasorelaxant effects produced by AECP were completely abolished in aortic rings preincubated with LNAME, ODQ and methylene blue, thus confirming the involvement of the NO-cGMP pathway in the relaxant effects of AECP (fig. 6a-c).

Involvement of Other Mechanisms in the Vasorelaxant Effects of AECP on Rat Aortic Rings

Atropine antagonist failed to block the relaxation produced by AECP after preincubation in endothelium-in- 


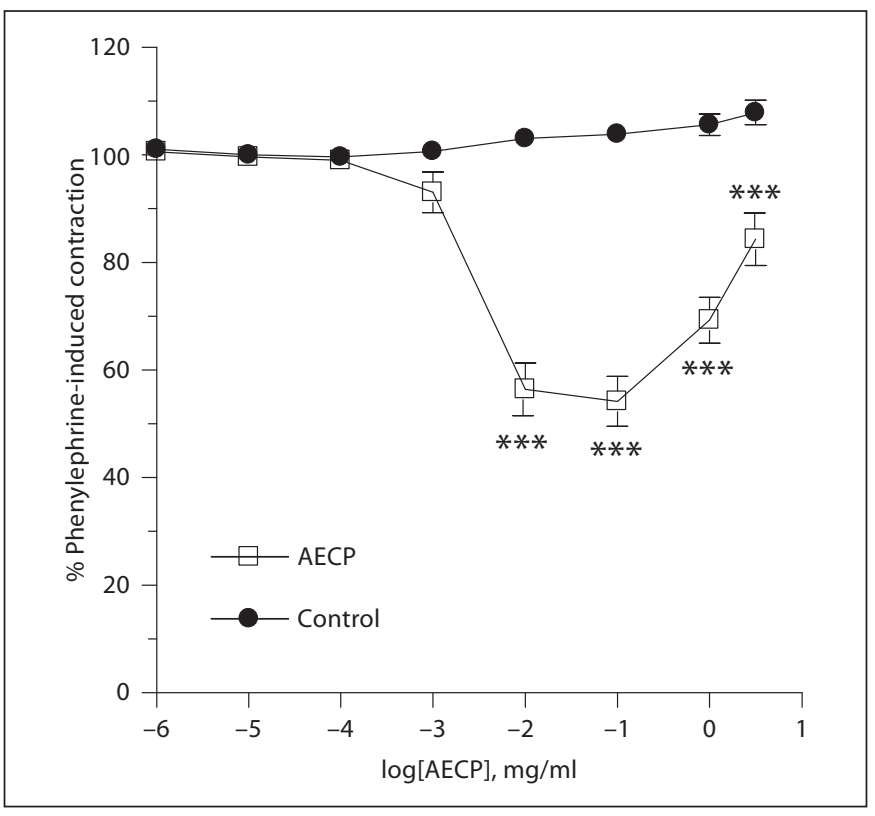

Fig. 4. Effects of crude aqueous extract of AECP on phenylephrine $(0.3 \mu \mathrm{M})$-induced contraction in endothelium-intact aortic rings isolated from Wistar-Kyoto normotensive rats. The results show the mean \pm SEM of 8 observations. ${ }^{* *} \mathrm{p}<0.001$ when compared to the control.

tact aortic rings (fig. 7). Pretreatment of aortic rings with a non-selective cyclooxygenase (COX) inhibitor, indomethacin, did not block the AECP-induced relaxation in aortic rings (fig. 8). An ATP-sensitive $\mathrm{K}^{+}$channel blocker, glibenclamide, did not block the aortic relaxation induced by AECP after preincubation of the endotheliumintact aortic rings but rather potentiated the relaxant effect at extract concentrations 0.1 and $1 \mathrm{mg} / \mathrm{ml}$ (fig. 9) compared to the control.

\section{Discussion}

In this present study, 11 species of seaweeds obtained from Malaysian coastal waters were screened for antihypertensive properties. We found that crude aqueous extracts derived from a brown alga, $P$. tetrastromatica, and a green alga, $C$. patentiramea, elicited a vasorelaxant effect in the PE-precontracted aortic rings of WKY rats. This is in agreement with a previous study conducted by Ren et al. [8], whereby the levels of systolic blood pressure of male Wistar rats fed with high concentrations of salt and a cholesterol-rich diet were lowered when various species of seaweeds and their polysaccharides were fed to the rats.

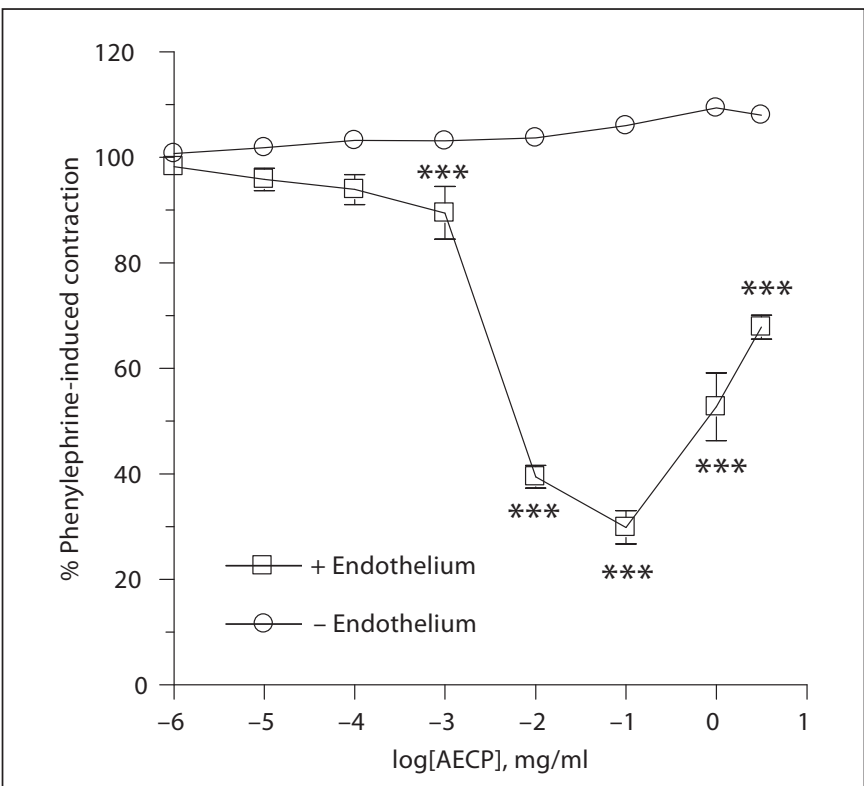

Fig. 5. Cumulative concentration-response of AECP constructed on $\mathrm{PE}$-induced contraction in aortic rings in the presence and absence of endothelium. The results show the mean \pm SEM of 5-6 observations. ${ }^{* *} \mathrm{p}<0.001$ when compared to the relaxation induced on endothelium-intact aortic rings.

On the other hand, crude aqueous extracts derived from the other 9 species of seaweeds caused PE-precontracted aortic rings to contract even further, suggesting the presence of vasoconstricting compounds in the seaweeds. Although various Sargassum species (brown algae) and Gracilaria species (red algae) have been shown to lower blood pressure in rats [8], our study showed a vasoconstrictive effect of the Sargassum species and G. salicornia crude aqueous extracts on WKY rat aortic rings. This difference might be due to factors such as species variation and environment of the seaweeds collected as different species of seaweeds, although from the same family, contain different bioactive compounds, and seaweeds growing in the temperate waters might have compounds different from those in the tropical seaweeds.

The crude aqueous extract derived from green alga, $C$. patentiramea (AECP), was selected for further pharmacological studies due to its higher vasorelaxant effect and reproducibility of the results. We found that AECP extract elicited a significant and concentration-dependent vasorelaxant effect on WKY rat aortic rings. This vasorelaxant effect was mainly dependent on the presence of an intact endothelium as removal of the endothelial layer completely abolished the relaxant action of the extract. Pretreat- 


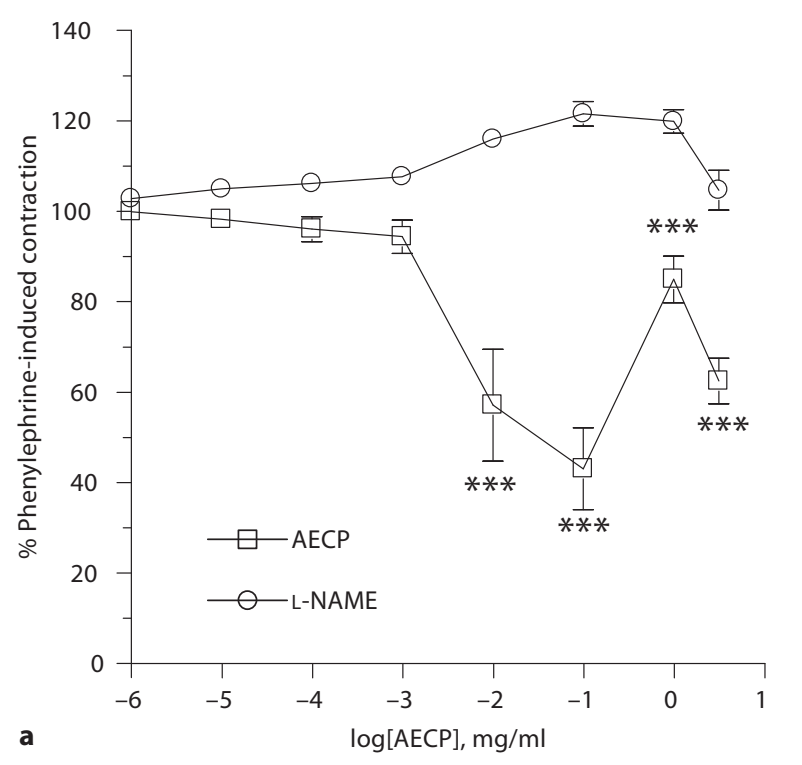

Fig. 6. Role of nitric oxide and soluble guanylate cyclase in the vasorelaxant action of AECP extract. a Effects of nitric oxide synthase inhibitor L-NAME $(30 \mu \mathrm{M})$ on the vasorelaxant effect induced by AECP. b, c Effects of AECP on aortic rings pretreated with soluble guanylate cyclase inhibitors, ODQ $(10 \mu \mathrm{M})$ and methylene blue $(100 \mu \mathrm{M})$. All the experiments were conducted using endothelium-intact aortic rings. The results show the mean \pm SEM of 5-7 observations. ${ }^{* *} \mathrm{p}<0.01$ and ${ }^{* * *} \mathrm{p}<0.001$ when compared to the AECP effects in absence of antagonists.

ment with a NO synthase inhibitor, L-NAME, and soluble guanylate cyclase inhibitors, ODQ and methylene blue, respectively, significantly removed the vasorelaxant effect induced by AECP extract in rat aorta, suggesting that $\mathrm{NO}$ synthase, an enzyme which synthesizes NO from the amino acid L-arginine, plays an essential role in the vascular relaxant action of the extract. It has been shown that once NO is released from the endothelial cells, it diffused into the adjacent arterial smooth muscle to activate guanylate cyclase and thus increase cGMP (cyclic guanosine mono-
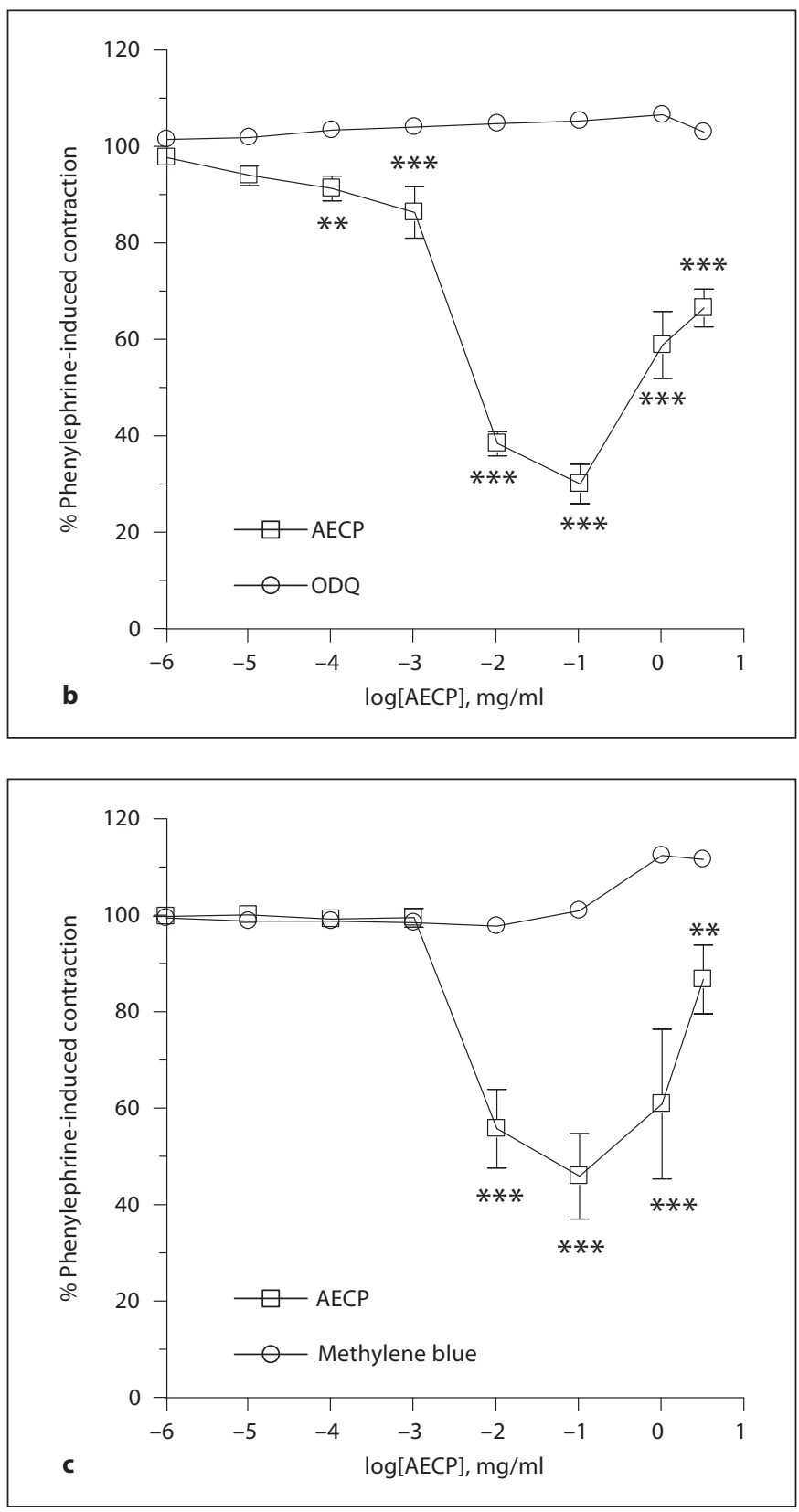

phosphate) formation, which subsequently leads to vascular smooth muscle relaxation [9]. Hence, complete inhibition of AECP-induced relaxation by ODQ and methylene blue further indicated that the active components contained in AECP extract act on the vascular endothelium via the NO-cGMP pathway.

In addition to NO, prostacyclin, the major product of the cyclooxygenase pathway in vascular endothelial cells, is another endothelium-derived relaxing factor involved in the control of vasomotor tone [10]. This vasodilator 


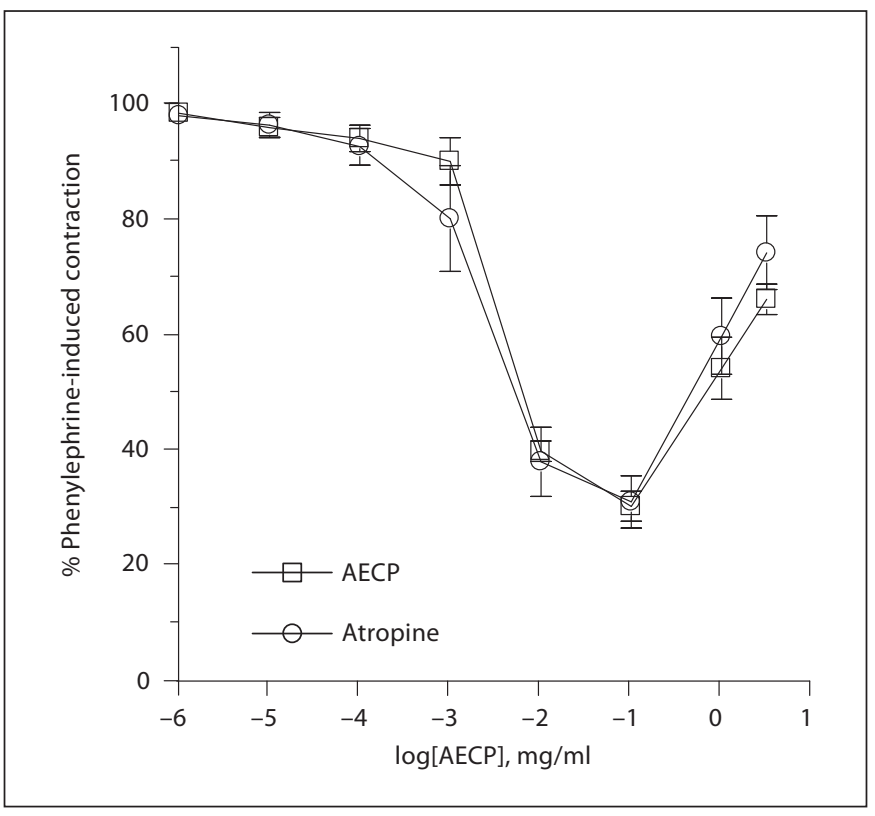

Fig. 7. Endothelium-intact aortic rings were pre-incubated with atropine $(1 \mu \mathrm{M})$ to evaluate the participation of the endothelial muscarinic receptors in the vasodilator effect of AECP. The results show the mean \pm SEM of 6 observations.

substance is rapidly synthesized and released in response to intracellular calcium elevation [11-13] and induces vascular smooth muscle relaxation via elevation of cAMP (cyclic adenosine monophosphate) and subsequent protein kinase A activation [14]. Many agonists, such as ACh, bradykinin and adenosine triphosphate, which stimulate the synthesis and release of NO, can also elicit prostacyclin release [12]. Therefore, to evaluate the involvement of prostacyclin in the AECP-induced vasorelaxation method, the rat aortic rings were pretreated with indomethacin, a non-selective cyclooxygenase inhibitor, prior to the addition of cumulative concentrations of AECP. The vasodilator prostaglandins did not participate in the relaxant effect of AECP as indomethacin did not block the extract-induced vasorelaxation in rat aortic rings (fig. 8).

Under physiological conditions, NO is continuously released by vascular endothelial cells as a consequence of the shear stress generated by blood flow [15]. Nonetheless, the release of $\mathrm{NO}$ can also be stimulated by muscarinic receptor activation [16]. Hence, we evaluated the possible involvement of muscarinic receptors in the vasorelaxant action of AECP. However, unlike ACh, the active components of AECP extract cause endothelium-derived NO release via a mechanism independent of the muscarinic re-

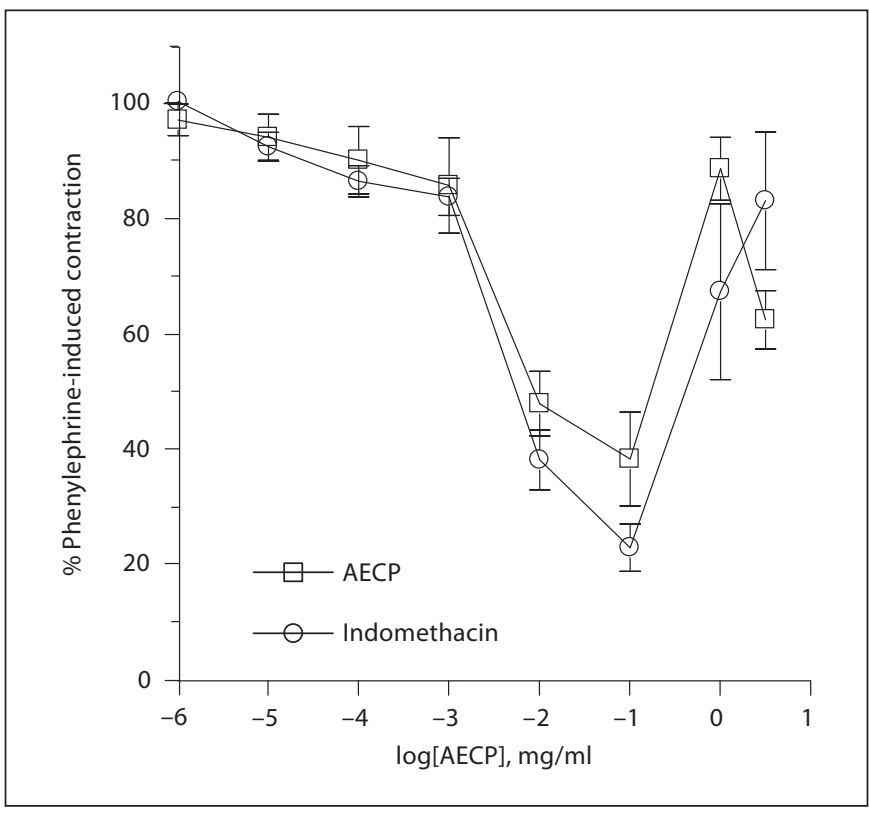

Fig. 8. Effects of AECP extract in the presence of cyclooxygenase inhibitor, indomethacin $(10 \mu \mathrm{M})$, using endothelium-intact aortic rings. The results show the mean \pm SEM of 5-7 observations.

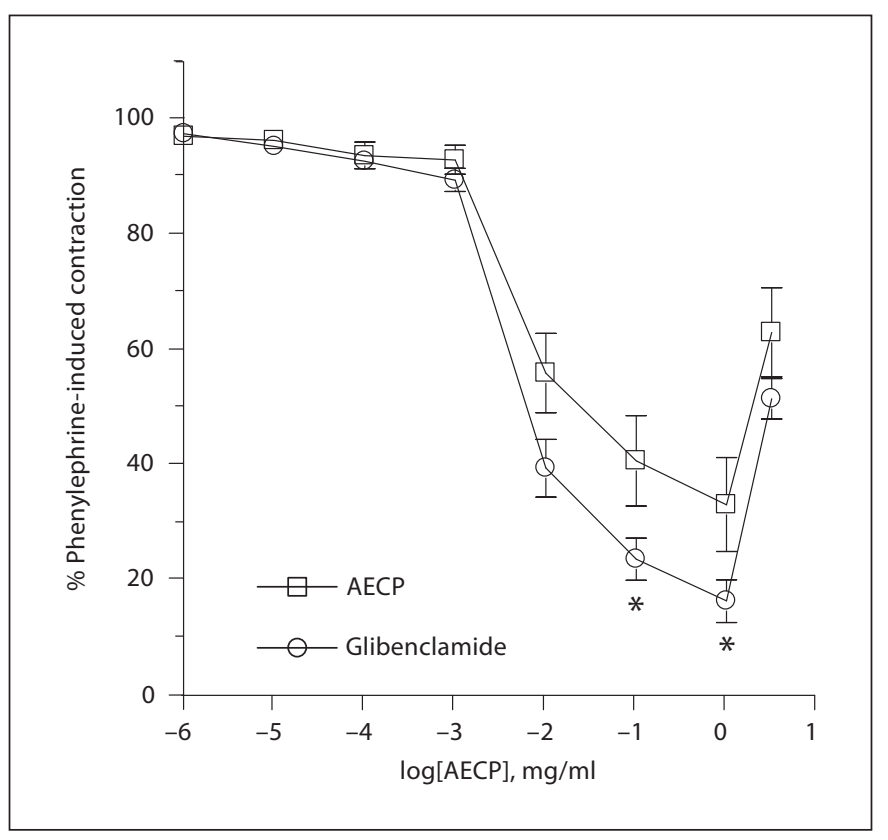

Fig. 9. Relaxant response of AECP extract in endothelium-intact aortic rings pre-incubated with $\mathrm{K}_{\mathrm{ATP}}$ channel blocker (glibenclamide, $10 \mu \mathrm{M})$. The results show the mean \pm SEM of $6-8$ observations. ${ }^{*} \mathrm{p}<0.05$ when compared to the AECP effects in absence of antagonist.

Med Princ Pract 2010;19:260-268 
ceptors as pretreatment with $1 \mu \mathrm{M}$ atropine, a competitive cholinergic muscarinic receptors antagonist, did not affect the vasorelaxation induced by AECP extract.

Modulation of potassium channels plays an important role in endothelium-derived NO synthesis and release [17]. NO is known to cause membrane hyperpolarization by activating ATP-sensitive potassium $\left(\mathrm{K}_{\mathrm{ATP}}\right)$ channels in vascular smooth muscle [18]. Furthermore, the opening of potassium channels can derive from direct action of NO [19] or the consequent activation of both guanylate cyclase and protein kinase G [20]. However, our results indicated that $\mathrm{K}_{\mathrm{ATP}}$ channels were not likely to be involved in AECP-induced vasorelaxation as this effect was not blocked by glibenclamide, a $\mathrm{K}_{\mathrm{ATP}}$ channel inhibitor.

\section{Conclusion}

Two out of 11 species of seaweeds collected from Malaysian coastal waters possessed antihypertensive properties and the aqueous extract derived from a green alga,
C. patentiramea, elicited vasorelaxant action in WKY rat aortic rings. The pharmacological mechanism of this action is likely to be mediated through endothelium-dependent NO-cGMP pathway. Isolation and identification of the active ingredient(s) in C. patentiramea is beyond the scope of our current study. Nonetheless, preliminary investigation with thin layer chromatography showed a possible ninhydrin-positive outcome (results not shown). The results obtained were inconclusive, but the basis from this preliminary chemistry work will warrant future investigations.

\section{Acknowledgements}

Yee-Ling Lim is a recipient of the National Science Fellowship awarded by the Ministry of Science, Technology and Innovation (MOSTI), Malaysia. We acknowledge the financial support of IRPA (grant No. 12-02-03-2072) from MOSTI, Malaysia, and also the Fundamental Grant (FP055/2005C) and Research University Special Grant (SF087-2007A) from University of Malaya, Malaysia.

\section{References}

1 Smit AJ: Medicinal and pharmaceutical uses of seaweed natural products: a review. J Appl Phycol 2004;16:245-262.

2 Lincoln RA, Strupinski K, Walker JM: Bioactive compounds from algae. Life Chem Rep 1991;8:97-183.

3 Hata Y, Nakajima K, Uchida J, Hidaka H, Nakano T: Clinical effects of brown seaweed Undaria pinnatifida (Wakame) on blood pressure in hypertensive subjects. J Clin Biochem Nutr 2001;30:43-53.

4 Suetsuna K, Nakano T: Identification of an antihypertensive peptide from peptic digest of wakame (Undaria pinnatifida). J Nutr Biochem 2000;11:450-454.

5 Sato M, Hosokawa T, Yamaguchi T, Nakano T, Muramoto K, Kahara T, Funayama K, Kobayashi A, Nakano T: Angiotensin I-converting enzyme inhibitory peptides derived from wakame (Undaria pinnatifida) and their antihypertensive effect in spontaneously hypertensive rats. J Agric Food Chem 2002;50:6245-6252.

6 Suetsuna K, Maekawa K, Chen JR: Antihypertensive effects of Undaria pinnatifida (wakame) peptide on blood pressure in spontaneously hypertensive rats. J Nutr Biochem 2004;15:267-272.

$\checkmark 7$ Ren D, Noda H, Amano H, Nishino T, Nishizawa K: Antihypertensive and antihyperlipidemic effects of funoran. Fish Sci 1994;60:423-427.
8 Ren D, Noda H, Amano H, Nishino T, Nishizawa K: Study on antihypertensive and antihyperlipidemic effects of marine algae. Fish Sci 1994;60:83-88.

$\checkmark 9$ Kwan CY, Chen CX, Deyama T, Nishibe S: Endothelium-dependent vasorelaxant effects of the aqueous extracts of the Eucommia ulmoides Oliv. leaf and bark: implications on their antihypertensive action. Vascul Pharmacol 2003;40:229-235.

10 Vanhoutte P: Endothelium and control of vascular function. State of the Art lecture. Hypertension 1989;13:658-667.

11 Moncada S, Gryglewski R, Burting S, Vane JR: An enzyme isolated from arteries transforms prostaglandin endoperoxides to an unstable substance that inhibits platelet aggregation. Nature 1976;263:663-665.

12 Nilius B, Droogmans G: Ion channels and their functional roles in vascular endothelium. Physiol Rev 2001;81:1415-1459.

13 Lima RF, Criddle DN, Souza EP, Sampaio AH, Nascimento KS, Cavada BS, Assreuy AMS: Red marine alga Bryothamnion triquetrum lectin induces endothelium-dependent relaxation of the rat aorta via release of nitric oxide. J Pharm Pharmacol 2004;56:1415-1421.

-14 Karaki H, Ozaki H, Hori M, Mitsui-Saito M, Amano K, Harada K, Miyamoto S, Nakazawa H, Won KJ, Sato K: Calcium movements, distribution and functions in smooth muscle. Pharmacol Rev 1997;49:157-230.
5 Rattmann YD, Cipriani TR, Sassaki GL, Iacomini M, Rieck L, Marques MCA, SilvaSantos JE: Nitric oxide-dependent vasorelaxation induced by extractive solutions and fractions of Maytenus ilicifolia Mart ex Reissek (Celastraceae) leaves. J Ethnopharmacol 2006;104:328-335.

16 Furchgott RF, Zawadzki JV: The obligatory role of endothelial cells in the relaxation of arterial smooth muscle by acetylcholine. $\mathrm{Na}$ ture 1980;288:373-376.

-17 Busse R, Edwards G, Feletou M, Fleming I, Vanhoutte PM, Weston AH: EDHF: bringing the concepts together. Trends Pharmacol Sci 2002;23:374-380.

18 Standen NB, Quayle JM, Davies NW, Brayden JE, Huang Y, Nelson MT: Hyperpolarizing vasodilators activate ATP-sensitive $\mathrm{K}^{+}$channels in arterial smooth muscle. Science 1989;245:177-180.

19 Bolotina VM, Najibi S, Palacino JJ, Pagano PJ, Cohen RA: Nitric oxide directly activates calcium-dependent potassium channels in vascular smooth muscle. Nature 1994;368: 850-853.

20 Archer SL, Huang JM, Hampl V, Nelson DP, Shultz PJ, Weir EK: Nitric oxide and cGMP cause vasorelaxation by activation of a charybdotoxin-sensitive $\mathrm{K}^{+}$channel by cGMPdependent protein kinase. Proc Natl Acad Sci USA 1994;91:7583-7587. 